\title{
O FIM DA FENOMENOLOGIA EM WITTGENSTEIN - UMA ABORDAGEM TEMPORAL ${ }^{1}$
}

Guilherme Ghisoni da Silva (UFG) ${ }^{2}$

ggsilva76@gmail.com

Resumo: Primeiramente, pretendo explorar a importância concedida por Wittgenstein, no período intermediário, à memória, no mundo primário/fenomenológico. De acordo com o autor, a memória será a fonte do tempo, do passado, do conhecimento e da identidade. O segundo e principal objetivo deste artigo é mostrar as razões de Wittgenstein para o abandono do projeto fenomenológico, pelo viés das análises do tempo (levando em consideração a ruptura com os papéis epistemológico e semântico, concedidos à memória). Para isso, buscarei explicitar uma falsa analogia, localizada por Wittgenstein, que nutria a busca por uma linguagem ideal. Essa falsa analogia poderá ser interpretada como o tratamento equivocado do passado da memória (em sentido fenomenológico), que levava à ilusão da possibilidade de um critério de exatidão da descrição fenomenológica. Ao final do artigo, buscarei sinalizar a importância dessas discussões para a compreensão do chamado "argumento da linguagem privada".

Palavras-chave: memória; fonte; identidade; fenômeno.

\section{INTRODUÇÃO:}

Este artigo tem um duplo objetivo. Primeiramente, pretendo explorar a importância concedida por Wittgenstein, no período intermediário, à memória, no mundo primário/fenomenológico. Essa importância pode ser notada no

\footnotetext{
${ }^{1}$ Recebido: 12-09-2013/Aprovado: 11-11-2013/Publicado on-line: 17-02-2014.

${ }^{2}$ Guilherme Ghisoni da Silva é Professor Adjunto I na Universidade Federal de Goiás, Goiânia, GO, Brasil.
} 
modo como o Wittgenstein trata a memória como fonte (Quelle), em três acepções distintas: i) do ponto de vista ontológico: como "fonte do tempo" (cf. MS 108, p.3/1975, $\$ 49)^{3}$ (e do "conceito de passado" (cf. MS 107, P. 242 /1975, §19), ii) pelo viés epistemológico: como "fonte de nosso conhecimento, como verificação de nossas proposições" (cf. MS 108, P. 33 / 1975, \$49.) e iii) do ponto de vista semântico: como "fonte da identidade" (cf. MS 107, P. $242 / 1975, \$ 19$.) (nesse terceiro caso, não será a memória diretamente nosso objeto de estudo, mas o reconhecimento (Wiedererkennen)).

Através do tratamento da memória como fonte, Wittgenstein sinaliza o seu caráter primitivo (indefinível), a partir do qual tempo, passado, conhecimento e identidade serão concebidos, em sentido fenomenológico. Esses papéis (que argumentarei serem centrais à ideia de um dado imediato (cuja forma e multiplicidade lógicas seriam imediatamente dadas)) decorreriam do modo como a memória, em sentido fenomenológico, não seria uma mera faculdade de representação, mas como afirma o autor, "[...] uma determinada parte da estrutura lógica do mundo" (2005, P. 351). ${ }^{4}$

O segundo e principal objetivo deste artigo é mostrar as razões de Wittgenstein para o abandono do projeto fenomenológico, pelo viés das análises do tempo (levando em consideração a ruptura com os papéis epistemológico e se-

\footnotetext{
${ }^{3}$ As referências dos manuscritos e tiposcritos de Wittgenstein (1989) serão feitas por meio das siglas "MS" e "TS" respectivamente. Em decorrência do uso frequente na bibliografia secundária, as citações do livro Philosophical Remarks (WITTGENSTEIN 1975) farão referência aos parágrafos da obra.

${ }^{4}$ Esse primeiro momento receberá um tratamento menos detido. O estudo em detalhes de como essas consequências epistemológica e semântica se relacionam com o papel ontológico da memória como fonte encontra-se em um outro artigo meu, intitulado "Recognition and Identity: Memory as Part of the Logical Structure of the World", que atualmente está no prelo.
} 
mântico, concedidos à memória). Para isso, farei uma análise detida do ditado a Waismann, intitulado "Linguagem Fenomenal" (WITTGENSTEIN 2003). Através desse ditado, buscarei explicitar uma falsa analogia, localizada por Wittgenstein, que nutria a busca por uma linguagem ideal. Essa falsa analogia poderá ser interpretada como o tratamento equivocado do passado da memória (em sentido fenomenológico), que levava à ilusão da possibilidade de um critério de exatidão da descrição fenomenológica. Uma vez desfeita a falsa analogia, Wittgenstein abandonará a ideia de que os fenômenos pudessem determinar a multiplicidade lógica que a linguagem deveria ter, para que o sentido fosse plenamente determinado.

Antes de dar início a essas análises, é importante lembrar que, mesmo após o abandono da linguagem fenomenológica, no início de 1929 (cujo fim é sacramentado em outubro de 1929 (MS 107, p.176)), Wittgenstein ainda toma os fenômenos como os fazedores de verdade das proposições genuínas. Desse modo, os fenômenos ainda determinariam o horizonte intencional da linguagem (a totalidade do que pode ser dito/verificado). Além disso, seu novo método filosófico, da comparação dos diferentes modos de representação (também expresso em outubro de 1929), busca "apreender a essência do que é representado" e corresponderia à "construção da linguagem fenomenológica" (cf. MS 107, 105-106 / 1975, §1). Esses são claros indícios de que o projeto fenomenológico de Wittgenstein se estende para além da tentativa de uma efetiva construção da linguagem fenomenológica (malograda já no final do MS 105 - presente no capítulo VII do livro Philosophical Remarks (1975)). E é a ruptura com a fenomenologia, nesse sentido mais amplo, que buscarei explicitar, pelo viés do tempo, 
através da análise do PS.

\subsection{A MEMÓRIA COMO A FONTE DO TEMPO:}

No início do MS 105, de fevereiro de 1929, Wittgenstein constata que o tempo é um tema privilegiado, ao notar que não entraria nas considerações do espaço visual como um "penduricalho" (cf. MS 105, P. 11). Como ele afirma, "[...] uma imagem visual pode apenas existir no tempo" (MS 106, P. 55 / 1975, §88 (grifos do autor)). Além disso, até mesmo "[...] dizer que tudo permanece o mesmo já pressupõe o tempo" (MS 105, P. 72).

O tempo mencionado nessas passagens não é o tempo homogêneo da física, cuja topologia se assemelha a uma linha, mas o tempo em sentido fenomenológico, da experiência imediata (que ele chama de "tempo primário" (cf. MS 106, P. 29 / 1975, §140)). Uma das dificuldades, referente ao tempo primário, é que, no âmbito da experiência imediata, somos tentados a dizer que "[...] apenas a experiência presente tem realidade” (cf. MS 108, p.2 / 1975, §54). Essa exclusividade ontológica do presente leva o autor ao seguinte problema. Uma vez que o presente não se opõe ao passado e ao futuro (pois só o presente é real), sequer poderíamos chamá-lo de "presente" (pois "'presente' não seria usado aqui para distingui-lo do passado e do futuro" (MS 108, P. 4)) e, com isso, seríamos, aparentemente, forçados a admitir que o fenômeno é "atemporal" (zeitlos) (cf. MS 108, P. 4 / 1975, \$54). Wittgenstein expressa essa situação paradoxal, no final do MS 105: "[s]e o mundo do dado é atemporal [zeitlos], como diabos se pode então falar sobre ele" (MS 105, P. 96 / 1975, §48)? O que há de paradoxal é que se, por um lado, os dados imediatos podem apenas existir no tempo, por ou- 
tro, seriam, aparentemente, atemporais (pois, sequer poderíamos chamá-los de "presente").

A resposta de Wittgenstein a esta indagação (que pode ser interpretada como a sua recusa da atemporalidade do mundo primário/fenomênico) nos remete ao ponto de partida do papel ontológico concedido à memória como fonte (Quelle). Segundo Wittgenstein, haveria uma experiência (Erlebnis) que fundamenta (zu Grunde) o conceito de tempo (Zeitbegriff): "[...] uma percepção contínua da qual o presente é um ponto final e que se pode chamar num sentido mais amplo também de memória" (MS 105, P. 98). Sem esse sentido mais amplo de memória, a realidade fenomênica seria reduzida a um "presente puntiforme" (punktartige Gegenwart), atemporal, desconexo de outros momentos do tempo, no qual as ideias de fluxo temporal e ordem temporal não seriam possíveis (cf. MS 105, P. 98).

O ponto de confluência entre tempo e memória (que leva Wittgenstein a conceber a memória como a "fonte do tempo" (cf. MS 108, p.33 / 1975, §49)) é que a continuidade da percepção será condição de possibilidade da ordem de antes e depois das vivências. Podemos apenas saber que um fenômeno veio antes ou depois de outro, se esses fenômenos forem contíguos. É essa ordem dos dados da memória que será o tempo em sentido fenomenológico/primário, que se opõe ao tempo físico. Como afirma o autor:

Os dados de nossa memória são ordenados, essa ordem chamamos de "tempo da memória", em oposição ao tempo físico, a ordem dos eventos no mundo físico. (TS 212, P. 1362 / 2005, P. 364)

Nas conversas com o Círculo de Viena, Wittgenstein expressa essas ideias de forma ainda mais enfática:

Minhas memórias são ordenadas. Tempo é o modo como memórias são 
ordenadas. Então, o tempo é dado em conexão imediata com as memórias. Tempo é, por assim dizer, a forma como tenho memórias. (WAISMANN 1979, p.98 (grifos do autor))

Mas por que Wittgenstein trata o modo como as memórias são ordenadas como o tempo em sentido fenomenológico? Uma maneira de responder a essa indagação é notar que a exclusividade ontológica do presente leva a um colapso total entre passado e memória. É necessário que tenhamos memórias dos fenômenos, pois, sem isso, sequer teríamos o conceito de tempo e de passado (visto que a acepção mais ampla de memória é a experiência fundamental de que algo foi dado (cf. MS 107, P. 242 / 1975, §19)). Mas se apenas o presente tem realidade, não pode haver uma positividade ontológica dos fenômenos passados, que torne a memória (e a ordem da memória) algo que pudesse corresponder ou não a esse passado. $O$ resultado da exclusividade ontológica do presente seria, então, a indistinção entre a ordem da memória e a ordem de como os fenômenos foram dados, pois ser passado significará ser dado pela memória. É por essas razões que, em sentido fenomenológico, a memória não seria uma mera faculdade de representação, mas "[...] uma determinada parte da estrutura lógica do mundo" (2005, P. 351) e o tempo primário (dos fenômenos) denominado de "tempo da memória" (Gedächtniszeit) (cf. TS 212, P. $1362 / 2005$, P. 364).

Além disso, a ordem da memória não seria apenas o tempo em sentido fenomenológico, mas condição de possibilidade de toda e qualquer ordem temporal. O tempo físico (secundário) é apenas uma construção a partir da ordem temporal primária (cf. MS 105, P. 86-8). No tempo físico "[...] traduzimos relações temporais em espaciais" (2005, P. 353). Nessa tradução, representamos as relações transitivas, 
assimétricas e não-reflexivas de antes e depois (de como os fenômenos são temporalmente ordenados pela memória) por meio de relações espaciais transitivas, assimétricas e nãoreflexivas (por exemplo, "a direita de...", "a esquerda de...") (cf. RAMSEY 2006, p.158). Assim, sendo a memória a fonte da ordem primária, a partir da qual uma ordem temporal secundária/fisicalista poderia ser construída (por meio da espacialização das relações de anterioridade e posterioridade), ela será, para Wittgenstein, no período intermediário, a fonte de todo e qualquer conceito de tempo.

\subsection{A MEMÓRIA COMO A FONTE DA IDENTIDADE E COMO FONTE DO CONHECIMENTO:}

Há importantes consequências epistemológicas e semânticas, do papel atribuído à memória como fonte do tempo. Essas consequências podem ser sumarizadas através da ideia de que não só a ordem da memória seria a ordem do tempo primário, mas o conteúdo da memória seria o critério único do passado, em sentido fenomenológico. Dada à exclusividade ontológica do presente, não há um passado para além do passado da memória, que seja o seu fazedor de verdade. Isso leva a um duplo desdobramento (de consequências epistemológicas e semânticas). A memória, ela mesma, será o único fazedor de verdade das proposições fenomenológicas sobre o passado. O outro desdobramento diz respeito à identidade dos fenômenos. No que tange à atribuição de identidade a fenômenos sucessivos, Wittgenstein tomará o reconhecimento (Wiedererkennen) como a fonte da identidade.

\footnotetext{
${ }^{5}$ Ramsey explora essa ideia em seu manuscrito sobre o tempo, de tom wittgensteiniano, redigido, provavelmente, em 1928-29.
} 
Um fenômeno será o mesmo que outro anteriormente dado se e somente se eu o reconhecer como o mesmo. Vejamos, inicialmente, o papel semântico da memória como fonte da identidade (na seção seguinte, abordaremos o papel epistemológico, como fonte do conhecimento).

Jakko Hintikka foi o primeiro a notar, no período intermediário de Wittgenstein, a importância da memória para a identidade dos fenômenos. Segundo ele, para os "[...] objetos fenomenológicos não há critério de identidade através do tempo exceto a memória" (HINTIKKA 1996, P. 244 (grifos meus)). ${ }^{6}$ Podemos observar como Wittgenstein articula essa concepção, em uma passagem do MS 107:

Como eu sei que a cor deste papel, que chamo de "branco", é a mesma que vi aqui ontem? Porque a reconheço; e esse reconhecimento é minha única fonte desse conhecimento [Quelle für dieses Wissen]. Nesse caso, 'que é a mesma' significa que eu a reconheço! / Então também não se pode questionar se ela é realmente a mesma ou se eu poderia estar enganado; (se é a mesma e não apenas parece ser). (MS 107, P. $236 / 1975$, §16 (grifos do autor))

Em um primeiro momento, a resposta de Wittgenstein à indagação que abre o parágrafo parece perder de vista o problema em questão. Ele responde que é possível saber que a cor vista hoje é a mesma de ontem "reconhecendo-a" - como se negligenciasse o fato de que o problema em questão poderia ser reformulado da seguinte maneira: como posso saber que reconheço corretamente essa cor, de tal modo que possa saber que ela é a mesma que vi ontem? É no adendo à resposta que a relação entre a identidade dos

\footnotetext{
${ }^{6} \mathrm{O}$ tratamento dado por Hintikka a esse ponto não me parece consistente. Uma inconsistência pode ser notada, por exemplo, no trecho em que afirma: "[c]omo em Descartes, Wittgenstein não acreditava implicitamente no testemunho da memória" (1996, P. 264). A posição de Wittgenstein é claramente contrária a de Descartes, uma vez que a memória dos fenômenos não estaria sujeita aos equívocos causados pelo Gênio Maligno.
} 
fenômenos e o colapso entre passado e memória (decorrente da exclusividade ontológica do presente) transparece: "esse reconhecimento é minha única fonte de conhecimento aqui”. Em outros termos, não há nenhum outro passado que os dados da memória, de tal modo que o reconhecimento será, ele mesmo, o próprio critério. Portanto (e de uma maneira completamente antagônica ao que encontraremos no chamado "argumento da linguagem privada", das Investigações Filosóficas (2002), dado que inexiste uma distinção entre ser e parecer ser, as afirmações "é a mesma" e "eu a reconheço" se sobrepõem e, para Wittgenstein, em 1929. 30, determinariam a identidade da cor ao longo do tempo.

Com isso, fica evidente por que não haveria no período intermediário (no que tange aos fenômenos) espaço para algumas das questões centrais da filosofia tardia de Wittgenstein, subsumidas na forma da indagação acerca do que seja "seguir uma regra". Diante da questão "o que garante que eu saiba aplicar no futuro a palavra 'vermelho'?", o Wittgenstein intermediário responderia "reconhecendo a cor" - supondo haver (ou melhor: instituindo) uma relação interna entre a cor que é dada no presente e suas ocorrências no passado da memória. Esse acesso imediato ao passado permitiria, então, a Wittgenstein afirmar que é "[...] como se [...] estivesse dizendo que tenho um protótipo [Urbild] que poderia a qualquer momento comparar com a cor" (MS 108, P. 59 / 1975, §11). Esse protótipo seria dado pela possibilidade de um acesso (via memória) ao fenômeno passado, que fixaria o referente do nome (sem que houvesse a possibilidade de erro, acerca da correção da memória - ser passado é ser dado pela memória).

Em resumo: do ponto de vista fenomenológico, como dirá Wittgenstein, "[...] reconhecimento é o que é primário 
e identidade secundário" (1975, §19). ${ }^{7}$ Isso torna os fenômenos perfeitos candidatos ao final da análise lógica da linguagem (colocando um fim ao regresso da determinação do sentido). Em algum momento da análise da linguagem chegaríamos a palavras cujos significados nos são imediatamente dados.

Outro desdobramento da memória como fonte é o seu tratamento como "fonte do conhecimento" (no qual será tomada como o fazedor de verdade das proposições fenomenológicas sobre o passado). Visto que a memória é o critério único dos fenômenos passados, no âmbito da experiência imediata, através da memória, não teríamos uma mera representação do passado (uma imagem), mas o passado, ele mesmo, em sentido fenomenológico. E é em decorrência desse tratamento da memória como um modo de "perceber o passado" (cf. MS 105, P. 96 / 1975, §50), que o autor atribui a ela o importante papel epistemológico, como "fonte de nosso conhecimento, como verificação de nossas proposições" (cf. MS 108, P. 33 / 1975, §49).

O papel epistemológico da memória como "fonte do conhecimento" é ilustrado por Wittgenstein, em uma passagem das conversas com o Círculo de Viena, em que explora a distinção entre a memória dos fenômenos e dos objetos físicos:

Se eu posso verificar uma especificação temporal - por ex., que tal e tal veio antes que tal e tal - apenas através da memória, 'tempo' deve ter um sentido diferente do caso onde eu posso verificar uma tal especificação por outros meios, por ex., lendo um documento, ou perguntando a alguém e assim por diante. [...].

\footnotetext{
${ }^{7}$ É importante notar que nesse trecho "primário" e "secundário" não fazem alusão ao fenomenológico e ao físico, mas a uma precedência lógica do reconhecimento em relação à identidade.
} 
Do mesmo modo, deve-se separar a memória como a fonte e a memória que pode ser verificada de um modo diferente. (WAISMANN 1979$, p. 53$)^{8}$

Principal ponto a ser notado é que, no "tempo" em que a memória é a fonte (ou seja, em seu sentido fenomenológico), ela será aquilo que determina o valor de verdade da proposição sobre o passado. Mas ela não será apenas um fazedor de verdade da proposição; ela será o único fazedor de verdade dessas proposições. Como afirma o autor, nesse caso: "eu posso verificar uma especificação temporal [...] apenas através da memória".

Só haverá a distinção entre passado e memória na acepção fisicalista de memória (em que ela é concebida como a memória de um evento físico). A grande diferença (que permite a distinção entre o sentido "primário" e "secundário" de memória) $)^{9}$ é que, no modo de representação fisicalista do tempo, concebe-se a existência dos eventos físicos como algo que independe da memória. Na estrutura sincrônica do tempo físico, o futuro é concebido como préformado e o passado como ainda existente. E é através dessa concessão de uma positividade ontológica ao passado, que a distinção entre ser passado e ser dado pela memória é alcançada, atribuindo à memória secundária o estatuto de mera representação bipolar do passado (que poderia ser verificada "lendo um documento, ou perguntando a alguém e

\footnotetext{
${ }^{8}$ Essa passagem nos permite afastar um equivoco interpretativo recorrente na bibliografia secundária - que diz respeito à suposição de que a linguagem fenomenológica deveria ater-se exclusivamente ao presente da experiência imediata (como sustenta Hintikka (1996) e Perrin (2007)). Wittgenstein traça aqui uma distinção entre dois sentidos que "tempo" têm e em ambos os casos atribui a possibilidade de proposições sobre o passado. O equívoco a ser afastado é a ideia de que no tempo fenomenológico apenas proposiç̃es sobre o presente teriam sentido.

${ }^{9}$ Embora essa terminologia remonte a William James (1918, P. 643), não estou aqui me comprometendo com o sentido atribuído a essas expressões por esse autor. O objetivo é justamente caracterizar o sentido peculiar dado por Wittgenstein às ideias subsumidas através dessas expressões.
} 
assim por diante" (cf. MS 108, P. 33 / 1975, §49 / 2005, P. 363)).

\section{O FIM DA FENOMENOLOGIA EM WITTGENSTEIN:}

Ao longo das próximas seções do artigo, buscarei mostrar, a partir da análise do ditado a Waismann, intitulado "Linguagem Fenomenal" (PS) (WITTGENSTEIN 2003), um modo de compreender o fim do período fenomenológico de Wittgenstein, pelo ponto de vista de suas análises sobre o tempo e a memória. Veremos inicialmente a estrutura argumentava do PS. Na seção seguinte, traçarei paralelos entre as ideias presentes no PS e as análises anteriores sobre o estatuto da memória no período intermediário.

Wittgenstein inicia o ditado indagando acerca da possibilidade de uma "[...] linguagem tão sutil que reproduz o menor dos detalhes [...] [e] nos desse a realidade completa" (P. 312). Em um primeiro momento, Wittgenstein levanta a possibilidade de que a descrição completa do campo visual não seja possível por uma inexatidão inerente à linguagem falada (Wortsprache). Para contornar essa suposta inexatidão (e mostrar que este não é o alvo ao qual sua crítica se destina - uma limitação da linguagem falada), ele recorre a dois estratagemas: i) a suposição de que a descrição do campo de visão seja feita por meio de um filme ${ }^{10}$ e ii) a ideia de que

\footnotetext{
${ }^{10}$ É interessante, inicialmente, notarmos que Wittgenstein, em seu primeiro cenário hipotético, lança mão da ideia de que a descrição do campo de visão seria feita por intermédio de um filme. No The Big Typescript - TS 213 (2005), Wittgenstein também descreve a linguagem fenomenológica (que poderia reproduzir os dados visuais em todos os seus detalhes) uma "(...) representação em filme" (P. 349). Claramente essa caracterização não poderia ser aplicada ao período inicial de 1929, visto que o filme é justamente o símile que representa o tempo físico. Isso permite concluir que a crítica presente no PS não simplesmente oferece uma nova crítica temporal à linguagem fenomenológica do início de 1929, mas é direcionada primariamente ao modo como o autor mantém a plena determinação do sentido após a ruptura com a linguagem fenomenológica. O filme Cont.
} 
poderíamos utilizar modelos (Muster) para alcançar essa exatidão completa. O que Wittgenstein buscará mostrar no PS é que, nesses casos (do filme e da utilização dos modelos), é possível conceber a exatidão de duas maneiras, nas quais são concedidos dois estatutos distintos ao passado da memória. Ele explora essa distinção através de um importantíssimo exemplo - que chamarei aqui de "exemplo do céu estrelado”. E será a localização (através desse exemplo) de uma falsa analogia na base de uma dessas concepções do passado da memória, que marcará o ponto de ruptura com a ideia da possibilidade de uma descrição completa da experiência imediata.

Segundo o autor, o filme ainda não seria uma descrição completamente exata do campo visual, pois o filme não poderia reproduzir o modo como no campo visual o olhar se move e dá proeminência a diferentes pontos, assim como, não reproduz a maneira como as bordas do campo de visão são borradas e indistintas. Desse modo, teríamos de dizer que o filme é apenas "[é] aproximadamente o que foi visto" (P. 3014).

O ponto explorado ao longo do PS é a indagação levantada logo na sequência. Ao dizermos que o filme é apenas aproximadamente o que foi visto, "[...] o que quer dizer 'aproximadamente' aqui" (P. 314)? O problema em questão (e que revela a pertinência das análises do tempo e da memória) é que, afirma Wittgenstein: "[d]o campo de visão, eu tenho

pode ser tomado como a exemplificação da maneira como ele concebe a plena determinação do sentido após o abandono da linguagem fenomenológica (através da distinção entre hipótese e proposição genuína). O filme é a uma série de imagens (as expectativas fenomenológicas - as proposições genuínas), dispostas em um tempo homogêneo fisicalista (como ilustrado pela metáfora do projetor). (Não nos esqueçamos de que em 1930 Wittgenstein ainda atribui o símile tractariano à proposição como imagem (Bild) (ao falar de sua natureza pictórica ("Bildhaftigkeit" - cf. MS 108, P. $58 / 1975, \S 10))$. 
apenas a memória, e é com base nessa memória que eu digo: 'era aproximadamente isto'" (P. 314/316). Ou seja, a questão "o que quer dizer 'aproximadamente' aqui?" tem como alvo a determinação do estatuto da memória com a qual a descrição (ou o filme) seria comparada e que serviria de critério para a exatidão da descrição da experiência imediata.

Há, segundo Wittgenstein, dois modos de conceber o sentido do termo "aproximadamente", nos quais se concede dois estatutos distintos ao passado da memória. Ele explora essa diferença através de um segundo estratagema. Wittgenstein nos instrui a supor que olhemos para uma cor e, logo em seguida, diante de alguns modelos (Muster) de cor, seríamos indagados "[...] se esta é a cor logo antes vista" (P. 316). Assim como no primeiro caso, é apenas com base na memória que poderíamos dar essa resposta e haveria (segundo Wittgenstein) duas respostas possíveis: “[n]ão posso mais me lembrar' ou 'é impossível me lembrar de modo tão exato"” (P. 316). O cerne do estratagema é que, no primeiro caso (em que se responde "não posso mais me lembrar"), o presente da experiência imediata é tratado como plenamente determinado e concede-se à memória um estatuto falho. Desse modo, supõe-se que a vagueza (Verschwommenheit) da memória poderia ser contraposta à plena exatidão de um presente que se perdeu no passado. Já no segundo caso (em que se responde "é impossível me lembrar de modo tão exato"), a vagueza (Verschwommenheit) não poderia ser contraposta a uma exatidão mais completa. Essa impossibilidade tornaria, no segundo caso, sem sentido a questão acerca de uma exatidão completa da descrição da experiência imediata, pois, para Wittgenstein, o primeiro caso seria o resultado de uma falsa analogia, em que se concebe o passado da experiência imediata como uma imagem material (como ve- 
remos a seguir).

Para explicitar em que sentido a impossibilidade de se lembrar de modo tão exato torna a vagueza da memória algo que não se contrapõe à exatidão de um presente que desapareceu no passado (e como esse caso difere da resposta "não posso mais me lembrar" - em que se supõe falha a memória), Wittgenstein utiliza o exemplo do céu estrelado (no qual lança mão de um argumento semelhante ao utilizado pelo escritor Jorge Luis Borges, no seu "Argumentum Ornitologicum", porém, com o intuito de defender uma posição antagônica). ${ }^{11}$ Wittgenstein pede que imaginemos a seguinte situação: "[a]lguém levanta/eleva os olhos, o tempo de um piscar de olhos, na direção do céu estrelado; e nós lhe interrogamos quantos pontos luminosos ele viu" (P. 318). Para Wittgenstein, há aqui também duas respostas possíveis (que tornariam evidentes as consequências da distinção entre as duas respostas do estratagema que recorre ao uso dos modelos de cores). Uma delas seria dizer que "eu vi n pontos de luz" (P. 318). Nesse caso, "[...] eu não sei quantos pontos luminosos eu vi, mas eu devo certamente ter visto um número definido” (P. 318). Entretanto, dirá Wittgenstein, que a única resposta correta aqui seria: "eu vi inumeráveis estrelas" (P. 318). ${ }^{12}$

\footnotetext{
${ }^{11} \mathrm{O}$ argumento na versão de Borges é o seguinte: "Fecho os olhos e vejo um bando de pássaros. A visão dura um segundo ou talvez menos; não sei quantos pássaros vi. Era definido ou indefinido o seu número? O problema envolve o da existência de Deus. Se Deus existe, o número é definido, porque Deus sabe quantos pássaros vi. Se Deus não existe, o número é indefinido, porque ninguém pode fazer a conta. Nesse caso, vi menos de dez pássaros (digamos) e mais de um, mas não vi nove, oito, sete, seis, cinco, quatro, três ou dois pássaros. Vi um número entre dez e um, que não é nove, oito, sete, seis, cinco etc. Esse número inteiro é inconcebível; Ergo, Deus existe" (2000, P. 184). Wittgenstein utiliza o mesmo argumento que Borges, porém, com o intuito de defender a posição antagônica; pois ele visa concluir, nos termos de Borges, que "o número é indefinido" (como veremos a seguir).

${ }^{12}$ Nessa segunda resposta, mesmo que não estejamos comprometidos com a ocorrência de um número determinado, ainda seria possível dizer que foram vistas milhares de estrelas, ou que, ao Cont.
} 
A aceitação de que nas duas afirmações não seja possível especificar o número de pontos luminosos parece sugerir que Wittgenstein passa a aceitar aqui uma forma de ceticismo da memória. Não apenas seria possível o erro da memória, mas isso seria algo inerente à rememoração do passado, pois ele sequer cogita a resposta "sim, é claro eu posso me lembrar". Porém, é justamente essa linha interpretativa que será alvo de sua crítica à primeira resposta em que se diz "eu vi n pontos de luz" (que é o desdobramento da afirmação "não posso mais me lembrar", do exemplo que recorre aos modelos de cor). A ideia de um ceticismo acerca da memória supõe não mais haver como determinar, exclusivamente a partir da memória, o número exato de pontos luminosos. Todavia, no momento em que o fenômeno foi dado, aceita-se que ele tinha um número determinado. Nesse caso, seria possível contrapor a inexatidão da memória à plena exatidão de um presente - que agora não é mais acessivel (pois desapareceu no passado).

Essa suposição de um presente plenamente determinado, que desaparece ao se tornar passado, será tratada por Wittgenstein como uma falsa analogia. Nessa analogia, diz o autor, "[...] confunde-se a imagem [Bild] procurada com uma imagem material [materiellen Bild]" (P. 316). Para a compreensão da importância dessa falsa analogia, é necessário notarmos como ela nos levaria à ideia da possibilidade de uma exatidão completa da descrição da experiência imediata. Ao tratarmos o passado da experiência imediata como

compararmos dois céus distintos, poderíamos dizer que há mais pontos em um que em outro (desse modo, teríamos aqui, segundo ele, “(...) um outro sistema de aritmética" (P. 318). Porém, alerta Wittgenstein, que, nesse caso, “(...) não se está descrevendo um número, mas uma impressão [Eindruck]" (P. 318). Assim, no que tange à semelhança como o Argumentum Ornitologicum, Wittgenstein escaparia à conclusão de Borges por aceitar esse outro sistema de aritmética e sustentar que o dado da memória descrito não é um numero, mas uma impressão. 
uma imagem material, supomos poder "[...] copiar a imagem de modo melhor ou pior, e aqui faria sentido dizer que a cópia reproduz exatamente o original"(P. 316/318). O ponto em questão é que, ao concebermos o passado como uma imagem material, supomos a possibilidade de uma descrição completamente exata da experiência imediata. Em algum lugar do passado, haveria o "original" da vivência passada, que (caso pudesse ser acessado) seria o critério para a exatidão da descrição fenomenológica da vivência passada.

Por esse viés, a impossibilidade de levarmos a cabo tal descrição fenomenológica (que seria um método de construção de uma linguagem ideal - de um simbolismo completamente perspícuo) não seria uma impossibilidade lógica, mas apenas uma "dificuldade técnica" da memória para acessar toda a completude dessa imagem do passado, que seria o critério de exatidão. Assim (no que tange ao exemplo do céu estrelado), pensamos que "[...] se eu pudesse mais uma vez voltar à experiência, poderia ver quantos pontos luminosos tinha" (P. 318). Ou seja, supõe-se que a vivência ainda existe no passado e que a dificuldade por detrás de uma descrição completamente exata seria a dificuldade (quase) física, de acessar o passado - como se estivéssemos ao lado de um quarto ao qual não podemos entrar, pelo fato da porta estar murada (cf. p 319).

\subsection{O PS E O TRATAMENTO DA MEMÓRIA COMO FONTE EM 1929-30:}

Vejamos agora alguns paralelos entre o PS e as ideias de 1929-30, acerca do estatuto da memória como fonte do conhecimento e da identidade. 
O primeiro ponto a ser notado é que o cerne da dificuldade que traz problema à ideia de uma plena determinação do sentido da descrição do campo visual no PS não é a quantidade excessiva de pontos luminosos (no cenário do céu estrelado). Nesse cenário do céu estrelado, Wittgenstein busca localizar a gênese do problema que, no cenário anterior, dizia respeito a apenas uma cor. Ou seja, o mesmo problema que se põe à descrição completamente exata de um campo de visão com milhares de pontos de luz deve também ocorrer para a descrição completamente exata de um campo de visão composto por apenas uma cor. Assim como no caso dos pontos luminosos no céu, teríamos duas opções de resposta, no que tange à rememoração da cor: $i$ ) poderíamos dizer que ela determina uma gradação exata (um número), mas que não conseguimos mais nos lembrar de modo tão exato (sendo esse caminho criticado por Wittgenstein) ou ii) poderíamos dizer que tal gradação seria uma possibilidade dentre inumeráveis outras e que nos seria impossivel lembrar de modo exato. Em ambos os cenários (da rememoração da cor e do céu estrelado), a posição defendida por Wittgenstein é que cada ponto ou cor seria a efetivação de uma possibilidade que exclui inumeráveis outras possibilidades - sendo-nos impossivel lembrar do que nos foi dado no campo de visão de modo tão exato (tomando o cuidado de não tratar essa impossibilidade como uma dificuldade técnica da memória, em acessar o passado). A grande chave de leitura para a compreensão do PS é que, não saber o número de estrelas visto (ou a exata gradação da cor), não significa que perdemos o número que nos foi dado no presente (por uma falha da memória). Tratar o presente como plenamente determinado (tendo um número determinado de estrelas, ou uma gradação específica de 
cor), mas inacessível em toda a sua completude ao se tornar passado, seria supor a existência (em algum lugar do passado) do original da vivência (a sua imagem material) - que se perdeu no fluxo temporal. Em outros termos, a impossibilidade de se lembrar do número de estrelas (ou a gradação exata da cor) não decorre de uma falha da memória para reter o passado (ou para acessar tal passado), mas da inexistência de um original da vivência plenamente determinado (que pudesse desempenhar o papel de critério de exatidão da descrição fenomenológica da realidade que nos foi dada).

Era justamente a ideia de um acesso ao "original" da vivência que Wittgenstein salvaguardava através do tratamento da memória como um modo de "perceber o passado", em 1929-1930. Necessariamente deveríamos saber se a cor presente nos modelos é ou não a cor logo antes vista ou quantos pontos luminosos foram vistos, pois a memória era o critério único dos dados imediatos passados. Desse modo, os dois cenários finais do PS (o da cor e do céu estrelado) confrontam duas das principais consequências do colapso entre passado e memória, que estavam presentes na filosofia de Wittgenstein, em 1929-30: i) o tratamento da memória como fonte da identidade (na qual a identidade do fenômeno seria dada de forma imediata - através do reconhecimento) e ii) como fonte do conhecimento (na qual a memória seria aquilo que verifica as proposições sobre o passado).

Em 1929-30, no que tange à determinação da identidade da cor, necessariamente deveríamos saber se a cor é ou não a mesma, pois a cor seria a mesma se e somente se a reconhecêssemos como a mesma (não havendo a possibilidade de engano do reconhecimento). Além disso, visto que a memória era um modo de "perceber o passado", deveríamos poder retornar à experiência passada, quantas vezes neces- 
sárias, para determinar o número de "pontos luminosos" vistos. Assim, ou bem um número exato de estrelas foi dado no presente da experiência imediata (e eu necessariamente devo saber esse número, pois a memória é o critério desse número - sendo este o caminho no qual Wittgenstein localiza a falsa analogia do passado como uma "imagem material"), ou nenhum número me foi dado (sendo esse segundo caminho o que Wittgenstein argumentará ser o correto, no PS).

Podemos, então, sumarizar a estrutura argumentativa do PS da seguinte forma (a partir da qual poderemos localizar como o PS se conecta - de forma crítica - com a concepção de memória primária sustentada por Wittgenstein em 1929-1930):

Questão inicial: sobre a possibilidade de uma linguagem que reproduz a realidade completa

Localização do problema temporal: "a experiência fugídia deixa-se capturar nos sinais"?

$$
\downarrow
$$

descrição do campo feita por meio de um filme

$$
\downarrow
$$

O filme é aproximadamente o que foi visto 
Questão central:

"o que quer dizer 'aproximadamente' aqui?"

Contraposição entre dois sentidos de memória, pois é com base na memória que se diz: "era aproximadamente isto"

\section{0 cenário:}

o uso de modelos para a determinação da cor
(A) caminho criticado
(B) caminho sustentado

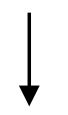

"não posso mais me lembrar" “é impossível me lembrar de modo tão exato"

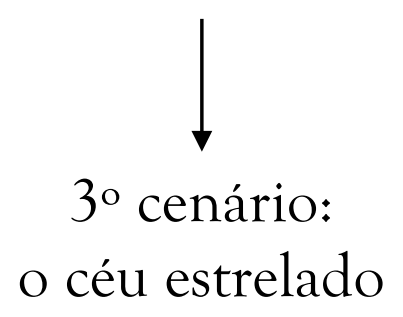

$\downarrow$

“eu vi $n$ pontos de luz"

"eu vi inumeráveis estrelas”

(localização da falsa analogia)

Podemos situar, dentro do esquema argumentativo do 
PS, a posição defendida por Wittgenstein em 1929-1930, do tratamento da memória como fonte do conhecimento e da identidade, da seguinte maneira:

caminho criticado $(\mathrm{A})$ se
bifurcaria em duas vias

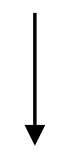

20 cenário:

o uso de modelos

(A1) caminho criticado no PS (A2) caminho que seria defendido em 1929-1930

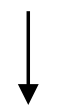

"não posso mais me lembrar da "eu reconheço imediatmente a cor" identidade da cor" (memória como fonte da identidade)

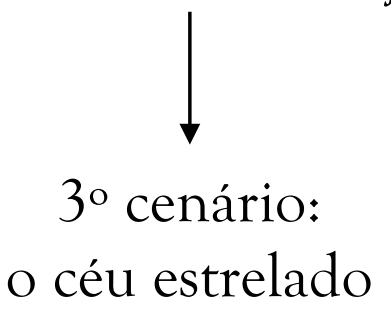

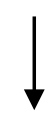

"eu vi $n$ pontos de luz" (mas não sei o valor de $n$ ) "eu vi $n$ pontos de luz" (e eu sei o valor de $n$ ) (memória como fonte do conhecimento)

Enquanto em (A1) atribui-se um estatuto falho à me- 
mória (como a dificuldade técnica de acesso - mencionada por Wittgenstein no PS), no caminho (A2), em decorrência do tratamento da memória como fonte do conhecimento e da identidade, o acesso ao original da vivência estaria garantido. Por exemplo, no caso do cenário 2, Wittgenstein não apenas diria, em 1929-1930, que posso me lembrar da cor vista, mas que o reconhecimento da cor como a mesma anteriormente dada seria a "[...] única fonte desse conhecimento" (MS 107, P. $236 / 1975$, \$16 (grifos meus)). Desse modo, a resposta criticada por Wittgenstein no PS, de que "não posso mais me lembrar [da cor]" pode ser interpretada como o espectro invertido da posição de 1929-1930, na qual a memória era a "fonte da identidade".

Entretanto (e esse é o ponto crucial), não haveria nos caminhos (A1) e (A2) (a partir da relação que traçamos entre as ideias do PS e as de 1929-1930) um dilema entre dois modos de tratar a memória, mas apenas um falso dilema decorrente de uma falsa analogia - que estaria na base de ambas as concepções. Embora o modo como o PS se constrói pareça sugerir que em (A1) o que está em questão é a limitação (empírica) da memória, o cerne da questão é a suposição ilusória de algo que pudesse desempenhar (do ponto de vista fenomenológico) o papel de critério para a exatidão da descrição da experiência imediata. Essa mesma falsa analogia estaria presente na suposição de um acesso irrestrito ao original da vivência (em (A2)), assim como, na negação de que tal acesso fosse possível (em (A1)). Desse modo, mesmo que Wittgenstein não expresse no PS uma crítica direta ao caminho (A2), essa via é apenas o outro lado da moeda, presente no caminho (A1) - sendo passível de dissolução através da localização da mesma falsa analogia. Pode-se dizer (à luz do PS) que, tanto em A1 quanto em A2, haveria o 
tratamento do passado fenomênico como a imagem material - como um original da vivência passada. A grande diferença é que, em 1929-30, ao tratar a memória como um modo de "perceber o passado", o acesso ao "original" da vivência estaria sempre garantido.

\section{CONCLUSÃO:}

Mas quais as consequências da localização da falsa analogia (presente no PS), do estatuto do passado da memória, para o desenvolvimento da filosofia de Wittgenstein?

Antes de tentar responder a essa indagação, gostaria apenas de pontuar que, embora não tenhamos como situar o PS cronologicamente (visto que esse texto não possui dada), do ponto de vista conceitual (no que tange às análises sobre o estatuto da memória), as ideias nele expressas poderiam ser localizadas a meio caminho entre os textos de 1929-30 e o The Big Typescript. No The Big Typescript, Wittgenstein afirma:

É simplesmente enganoso dizer: 'a memória me diz que essa é a mesma cor, etc.' $\mathrm{Na}$ medida em que ela me diz algo, ela pode também me enganar (por ex., dizer algo falso). / Se descrevo o passado imediatamente dado, então estou descrevendo minha memória e não alguma coisa para a qual essa memória aponta. (P. 351)

Aqui, claramente, Wittgenstein se opõe à tese expressa no parágrafo 16 das Philosophical Remarks, de que o "reconhecimento é minha única fonte" para a determinação da identidade dos fenômenos. No trecho do The Big Typescript, Wittgenstein afirma ser enganoso dizer que a memória determinaria a identidade da cor. Nesse mesmo trecho, ele também se afasta do tratamento da memória como modo de "perceber o passado". Wittgenstein critica, no final da 
passagem, a ideia de que na descrição do passado da experiência imediata pudéssemos descrever "alguma coisa para a qual essa memória aponta". Era o acesso imediato ao passado (àquilo ao qual a memória "aponta") que nos era garantido pelo tratamento da memória como "percepção do passado".

Pelo ponto de vista do desenvolvimento da filosofia do período intermediário, podemos expressar as consequências da localização da falsa analogia, presente no PS, recorrendo a uma passagem do MS 107, de janeiro de 1930. Segundo o autor:

A 'cor' que posso reconhecer imediatamente e aquela que estabeleço por meio de uma investigação química são duas coisas diferentes. De uma fonte flui apenas uma coisa (MS 107, P. 236 / 1975, §16 (grifo do autor)).

Nesse trecho de janeiro de 1930, podemos ver como a cisão, central ao período intermediário, entre dois sistemas hierarquicamente relacionados (o sistema primário/fenomenológico e o secundário/fisicalista), se expressa no que tange à identidade. Não haveria uma cor e dois modos de determinar a sua identidade (por meio do reconhecimento imediato ou por um critério fisicalista). Mas modos diferentes de determinar a identidade implicariam que falamos de coisas diferentes. E, em 1929-30, haveria a primazia do sistema fenomenológico (no qual a identidade dos fenômenos seria determinada pelo reconhecimento imediato), pois os fenômenos seriam os únicos fazedores de verdade das proposições genuínas.

A localização da falsa analogia no PS pode ser interpretada como a razão do abandono da ideia de que a memória pudesse nos dar a identidade da cor (através do seu reconhecimento imediato). Esse abandono levaria a uma grande 
ruptura, pois a noção de um sistema primário (fenomenológico) estava fundava na ideia de um dado imediato (cuja identidade nos seria imediatamente dada). Os fenômenos determinavam a forma e multiplicidade lógica da totalidade do que podia ser dito/verificado (fixando, assim, a gramática a partir da qual a física constrói suas teorias). Sem a ideia de um fenômeno (cuja identidade seria imediatamente dada), cai, então, por terra a tese (que remontaria à influência de Heinrich Hertz, Helmholtz e Botlzmann) de uma estrutura formal da experiência imediata (cf. HYDER 2002, P. $154-$ 155). A ideia de que o fenômeno tivesse uma forma e uma multiplicidade lógicas imediatamente dadas não passaria de uma ilusão, decorrente do estatuto não problemático da identidade dos fenômenos.

Do ponto de vista da linguagem, a localização da falsa analogia levaria ao abandono da ideia de uma linguagem ideal (completamente analisada). $\mathrm{O}$ período intermediário estava fundado na busca por uma notação completamente perspícua, cuja sintaxe seria isomórfica aos fenômenos (cf. WITTGENSTEIN 1929, P. 162, WAISMANN 1979, P. 249). Porém, visto que os fenômenos não teriam suas identidades imediatamente dadas, não faria mais sentido a busca por um simbolismo, cuja sintaxe lhes fosse isomórfica. Desaparecerá também a ideia de que a comparação entre simbolismos fisicalistas, que cumprem um mesmo propósito (o novo método filosófico de Wittgenstein, do final de 1929 (cf. 1975, §1)), pudesse mostrar a essência da linguagem - pois é justamente essa ideia de uma essência que desaparece através da constatação de que os fenômenos não têm forma e multiplicidade lógicas imediatamente dadas.

Isso leva ao fim a estratificação da realidade em dois sistemas (primário e secundário). Restará apenas falarmos da 
cor, como aquilo cuja identidade seria determinada por critérios fisicalistas (por exemplo, "por meio de uma investigação química”). E cada contexto de uso da linguagem fixará essa gramática, que determina a exatidão da linguagem, a partir da determinação dos seus modelos e padrões (fisicalistas).

Wittgenstein expressa semelhante conclusão, ao final do PS:

É melhor não fazer nenhuma generalização, mas explorar em cada caso individual o que poderia ainda ali ser chamado de "maior exatidão". Devemos perguntar: pode-se imaginar uma representação mais exata? Temos um critério para isso? Em um caso temos, em outro não, e então perde qualquer sentido falar em uma "possível maior exatidão" e assim também de uma "aproximatividade" da apresentação. (P. 320)

De acordo com essa passagem, a exatidão da descrição do mundo sempre estará atrelada ao contexto de uso e aos critérios (fisicalistas) de exatidão daquele contexto. Ou seja, sempre deveremos indagar se, naquele contexto, "temos um critério para isso?". Recorrendo à ideia presente no trecho citado do MS 107, caso tenhamos à disposição naquele contexto de uso da linguagem um método de investigação (químico/fisicalista), que nos permita determinar com maior exatidão se a cor é ou não a mesma, naquele contexto faria então sentido perguntar por uma maior exatidão. A mesma ideia pode ser estendida ao exemplo do cenário do céu estrelado (do PS). Apenas teria sentido a questão pela possibilidade de uma exatidão da determinação do número de pontos luminosos vistos no céu, caso tivéssemos algum critério para essa exatidão (como por exemplo, uma fotografia do céu estrelado). Mas, nesse caso, não estaríamos mais descrevendo o passado da memória (no tempo primário - 
aquilo ao qual a memória "aponta"), porém, um evento físico (situado no passado da ordem temporal secundária, e cuja existência no passado independe da memória).

Mas Wittgenstein não nega que possamos descrever a impressão fenomenológica. Nesse caso, teríamos de dizer que "é impossível me lembrar de modo tão exato". O que Wittgenstein nega é que a ordem e o conteúdo das memórias das impressões pudessem instituir um sistema primário, que mostraria as possibilidades da realidade, a partir das quais linguagens fisicalitas poderiam ser construídas. Dito de outra forma: a memória não poderá ser a última corte de apelação do sentido (e da exatidão das descrições da experiência imediata). Ela será apenas um guardião mais ou menos confiável do passado (cf. MS 108, P. 33 / 1975, §49 / 2005, P. 363).

Com essa mudança (e esse ponto terá profundas implicações para a filosofia madura de Wittgenstein), a gramática da linguagem que fala dos dados imediatos e fenômenos passará a ser parasitária do sentido e dos significados determinados de forma fisicalista (pois os únicos critérios à disposição seriam critérios fisicalistas). Essa mudança poderá ser tomada como o pano de fundo de algumas das análises posteriores, que culminarão na redação do chamado "argumento da linguagem privada". É a exigência de um critério fisicalista que se mostraria na ideia de que "[t]emos que falar de comportamento se falamos de nossa linguagem e seu uso" (WITTGENSTEIN 1993, P. 334). Como diz Wittgenstein, nas aulas de 1936, sobre a experiência privada: "[s]empre que fazemos uma afirmação que pareça ser behaviorista, o essencial é que damos um modelo. O que é behaviorista é o modelo que eu dou" (1993, P. 339). Nos termos de 1929-30, o recurso a um modelo behaviorista, 
para a determinação da gramática da palavra "dor", seria a expressão da necessidade de critérios baseados em modelos e padrões fisicalistas. $O$ modelo não poderá ser algo no "tempo da memória" (em que a memória é a fonte), mas algo no "tempo físico", tendo como critério de identidade algo que independa da memória. Como dirá Wittgenstein em 1936: "[...] um modelo é, assim como uma palavra, algo que perdura" (1993, P. 340-341). ${ }^{13}$

Essas ideias ecoarão na filosofia tardia de Wittgenstein, nas seções do "argumento da linguagem privada" (2002, §243-315). A importância do PS é que ele nos mostra a gênese temporal da localização da confusão gramatical entre vivência/representação/fenômeno e coisa/objeto (que leva à suposição da possibilidade de uma linguagem privada), ao nos lembrar de que dos dados imediatos "[...] eu tenho apenas a memória, e é com base nessa memória que eu digo: "era aproximadamente isto"' (2003, P. 314/316). A suposição da possibilidade de uma linguagem fenomenológi$\mathrm{ca} /$ privada estaria diretamente relacionada ao tratamento do passado da memória como um coisa, ao qual supomos poder sempre recorrer, para determinar a exatidão e a identidade dos significados da linguagem, que supostamente descreveria a experiência imediata de forma também imediata.

Abstract: First I will explore the importance granted by Wittgenstein, in the middle period, to memory, in the primary/phenomenological world. According to him, memory is the source of time, past, knowledge and identity. The main objective of this article is to present Wittgenstein's reasons for the rejection of the phenomenological project, using as backdrop his analysis about time (and the abandonment of the semantical and epistemological roles granted to memory). For this purpose it will be crucial to understand a

\footnotetext{
${ }^{13}$ Neste trecho, o que estaria em questão seria o caráter necessariamente transtemporal dos modelos, em oposição ao estatuto temporalmente instantâneo dos fenômenos.
} 
false analogy, that according to him was the cause for the quest for an ideal language. This false analogy can be interpreted as the attribution of a mistaken status to memory (in the phenomenological sense), that leads to the illusion of a criteria of exactitude for the phenomenological description. At the end of this article, I will point out briefly the importance of those ideas to the understanding of the so called "private language argument".

Keywords: memory; source; identity; phenomenon.

\section{REFERÊNCIAS}

Borges, J. L., Obras Completas: Volume II 1952-1972, Editora Globo, São Paulo, 2000.

Hyder, D., The Mechanics of Meaning: Propositional Content and the Logical Space of Wittgenstein's Tractatus, Walter de Gruyter, Berlin/New York, 2002.

Hintikka, J., Selected Papers, vol. 1: Ludwig Wittgenstein: Half-Truths and One-and-a-Half-Truths [= SP, vol. 1], Netherlands, Kluwer Academic Publishers, 1996.

James, W., The Principles of Psychology, London, Harvard University Press, 1918.

Perrin, D., Le Flux et l'instant - Wittgenstein aux prises avec le mythe du présent, Paris, Vrin, 2007.

Ramsey, F., "Notes on Time", in: Cambridge and Vienna: Frank P. Ramsey and the Vienna Circle, Maria Carla Galavotti (Ed), Springer, Netherlands, 2006, P. 156-158.

Waismann, F., Wittgenstein and the Vienna Circle: conversations recorded by Friedrich Waismann, McGuinness (ed.), Basil Blackwell, Oxford, 1979.

Wittgenstein, L., "Some Remarks on Logical Form", In: Proceedings of the Aristotelian Society, Suppl. vol. 9 (1929) 
$162-171$

- Philosophical Remarks, Rhees, R.(ed). Transl. by Hargreaves, R. and White, R., Chicago, The University of Chicago Press, 1975.

. Wittgenstein's Nachlass - The Bergen Electronic Edition [= MS / TS], Clean Version (C) Copyright in this machine-readable text Hans Kaal and Alastair McKinnon, 1989.

. "The Language of Sense Data and Private Experience - Notes by Rush Rhess". Philosophical Occasions 19121951, Klagge, J. and Nordmann, A. (ed). Hackett, Indiana, 1993, p. 290-367.

. Philosophical Investigations, Third edition, Transl. by Anscombe, G. E. M., Oxford, Blackwell Publishing, 2002.

. "Phänomenale Sprache". In: The Voices of Wittgenstein (The Vienna Circle). Ludwig Wittgenstein and Friedrich Waismann. Ed: Baker. Original German Texts and English translations. Transcribed, edited and with an introduction by Gordon Baker. Routledge, 2003.

. The Big Typescript - TS 213, Luckhardt G.G. and Maximilian A.E (ed), Transl. by Luckhardt G.G. and Maximilian, Oxford, Blackwell Publishing, 2005. 
